\title{
A note on terms
}

The terminology of early modern composite states poses particular problems for modern Anglophone historians. To avoid confusion, I use the terms 'Savoy' and 'Savoyard' to refer specifically to the duchy of Savoy, while 'Piedmont-Savoy' and 'Sabaudian' are used for the composite possessions of the duke of Savoy.

'Lorraine' designates the composite state of the dukes of Lorraine, except where I have indicated a distinction between the duchy of Lorraine and the duchy of Bar. Equally problematic is the rendering into English of Lorrain/Lorraine, which is both an adjective of nationality and the word for a native of Lorraine; in the interests of simplicity I use the form 'Lorrain' for both, e.g. the Lorrain nobility, a Lorrain. 